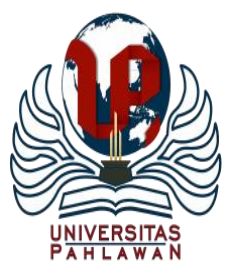

Jurnal Abdidas Volume 2 Nomor 5 Tahun 2021 Halaman 1092-1098

JURNAL ABDIDAS

http://abdidas.org/index.php/abdidas

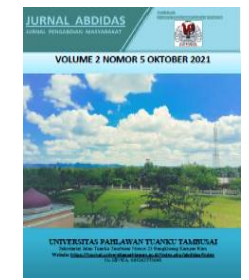

\title{
Persiapan Menghadapi Dunia Kerja bagi Mahasiswa Tingkat Akhir dan Lulusan Baru
}

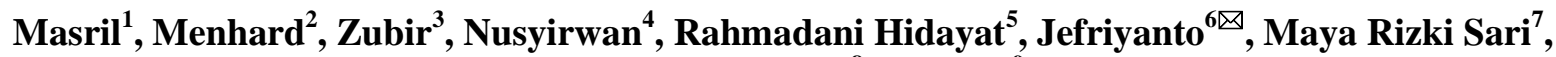 \\ Muhammad Yusuf ${ }^{8}$, Jonnedi ${ }^{9}$ \\ Akuntansi, STIE Mahaputra Riau, Pekanbaru, Indonesia ${ }^{1,2,3,6,7,8}$ \\ Manajemen, STIE Mahaputra Riau, Pekanbaru, Indonesia ${ }^{4,5}$ \\ Pascasarjana Universitas Lancang Kuning, Pekanbaru, Indonesia ${ }^{9}$ \\ Email : Masrilsikumbang1967@gmail.com ${ }^{1}, \underline{\text { menhard1967@gmail.com }}^{2}$, zubirstiemahaputra@ gmail.com $^{3}$, \\ irwanplgpku@gmail.com ${ }^{4}$, rahmadanihidayat83@gmail.com ${ }^{5}$, jefriinfo@gmail.com $^{6}$, \\ mayarizkisarii@gmail.com ${ }^{7}, \underline{\text { alsyahbani.yusuf95@gmail.com }^{8}}, \underline{\text { khavin 82@yahoo.com }}^{9}$
}

\begin{abstract}
Abstrak
Persaingan dunia kerja yang semakin ketat membuat lulusan perguruan tinggi harus meningkatkan daya saing agar dapat memperoleh pekerjaan yang sesuai dengan harapan. Dalam kondisi seperti ini, kemampuan intelektual dan akademik yang tinggi saja tidak cukup untuk mudah mendapatkan pekerjaan. Kegiatan ini dilakukan untuk memberikan pemahaman dan pembekalan kepada mahasiswa tingkat akhir dan lulusan baru yang berada di lingkungan STIE Mahaputra Riau tahun 2021 sebelum memasuki dunia kerja. Hal ini didorong karena semakin ketatnya persaingan dalam dunia kerja, sehingga para pelaksana kegiatan ini merasa perlu jika para mahasiswa diberikan pengetahuan mendasar dalam memahami dunia pasca kampus dengan memberikan pencerahan menghadapi dunia kerja dari yang ahli di bidangnya. Kegiatan ini dilakukan secara daring dengan menggunakan media zoom dan di ikuti oleh sebanyak 78 peserta dan menghadirkan narasumber Kepala Administrasi Agung Automall yang memiliki banyak pengalaman dalam proses asesmen dalam organisasi, yaitu Ibu Refnelidha Yeva. Hasil dari kegiatan ini menunjukan bahwa para peserta menjadi lebih siap dalam menghadapi dunia kerja dan dapat menentukan pilihan yang akan diambil setelah memasuki dunia pasca kampus dilihat dari respon sebaran kuesioner evaluasi.
\end{abstract}

Kata kunci: pembekalan, persiapan, mahasiswa, dunia kerja, lulusan baru

\begin{abstract}
The increasingly fierce competition in the world of work makes university graduates have to increase their competitiveness in order to get jobs that match expectations. Under these conditions, high intellectual and academic ability is not enough to easily get a job. This activity is carried out to provide the understanding and briefing to final year and fresh graduates students of STIE Mahaputra Riau in 2021 before they entering the world of work. This is driven by the increasingly fierce competition in the world of work, the team of this activity though that its would be necessary if students are given basic knowledge in understanding for the post-campus world by providing enlightenment before they face the world of work from experts in their fields. This activity was carried out online activity using zoom apps and was attended by 78 participants and presented by head of Administration of Agung Automall who has a lot of experiences in the assessment process in organizations, namely Ms. Refnelidha Yeva. The results of this activity show that the participants are better prepared to face the world of work and can determine the choices to be made after entering the post-campus world seen from the response to the questionnaire of evaluation.
\end{abstract}

Keywords: preparation, students, world of work, fresh graduates

Copyright (c) 2021 Masril, Menhard, Zubir, Nusyirwan, Rahmadani Hidayat, Jefriyanto, Maya Rizki Sari, Muhammad Yusuf, Jonnedi

$\triangle$ Corresponding author

Address: STIE Mahaputra Riau

ISSN 2721- 9224 (Media Cetak)

Email : jefriinfo@gmail.com

ISSN 2721- 9216 (Media Online)

DOI : https://doi.org/10.31004/abdidas.v2i5.431 
1093 Persiapan Menghadapi Dunia Kerja bagi Mahasiswa Tingkat Akhir dan Lulusan Baru - Masril, Menhard, Zubir, Nusyirwan, Rahmadani Hidayat, Jefriyanto, Maya Rizki Sari, Muhammad Yusuf, Jonnedi

DOI: https://doi.org/10.31004/abdidas.v2i5.431

\section{PENDAHULUAN}

Wisuda berarti memasuki fase awal dalam perubahan gaya hidup bagi seorang mahasiswa disetiap perguruan tinggi. Mereka bukan lagi mahasiswa, tetapi sekarang mereka akan menghadapi dunia sebagai profesional yang secara langsung memenuhi syarat administrasi. Mahasiswa adalah golongan intelektual yang mempunyai dua karakteristik yang menonjol, yaitu seorang pemuda dan calon intelektual (Prihastuti \& Rahmawati, 2012). Di luar sana, kemungkinan keberhasilan mereka di dunia kerja tergantung bagaimana mereka mengarahkan arti kelulusan mereka tersebut. Memiliki gelar sarjana, berarti persiapan karir yang akan mereka jalani nantinya sudah memasuki babak baru yang bersifat kondisional. Pemahaman tentang bagaimana menggunakan gelar yang mereka miliki sehingga mereka mampu bersaing dan membangun karir di luar, butuh pemahaman yang sangat mendalam. Banyak hal yang mereka harus tau sebelum langkah awal itu mereka laksanakan. Banyak penelitian yang telah dilakukan dan menemukan bahwa begitu seorang mahasiswa meninggalkan kampus tempat mereka belajar, mereka cenderung berhenti memiliki strategi dan komitmen khusus untuk tetap belajar. Padahal, Pengembangan pribadi dan profesional yang berkelanjutan sangat penting, jadi diperlukan proses selalu mencari peluang yang berkelanjutan untuk tetap tumbuh, bukan hanya mencari tempat untuk menunjukkan apa yang sudah mereka ketahui selama proses pembelejaran yang mereka lewati.
Perguruan Tinggi merupakan lembaga pendidikan formal yang mengemban amanah untuk menciptakan masyarakat akademik yang cakap ilmu dan menjadi agen perubahan sosial (agent of social change). Perguruan Tinggi juga secara formal merupakan pendidikan lanjutan yang mempunyai perbedaan cukup mendasar dengan pendidikan formal sebelumnya yaitu pendidikan menengah yang terdiri dari pendidikan menengah umum dan pendidikan menengah kejuruan baik yang berbentuk Sekolah Menengah Atas, Madrasah Aliyah, Sekolah Menengah Kejuruan dan Madrasah Aliyah Keagamaan. Perguruan tinggi bertujuan memberikan ilmu pengetahun dan skill kepada mahasiswa yang akan mempersiapkan diri untuk terjun kedunia industri dan dunia usaha. Dengan berkembang pesatnya sistem informasi dan teknologi pada zaman sekarang ini mengakibatkan selektifnya perusahaan, dunia usaha, dan dunia industri untuk merekrut tenagatenaga kerja yang berkompeten dibidang Informasi Teknologi. Persaingan dunia kerja yang semakin ketat membuat lulusan perguruan tinggi harus meningkatkan daya saing agar dapat memperoleh pekerjaan yang sesuai dengan harapan. Dalam kondisi seperti ini, kemampuan intelektual dan akademik yang tinggi saja tidak cukup untuk mudah mendapatkan pekerjaan.

Lulusan harus mampu memahami kompetensi yang dibutuhkan dunia kerja, menggali kemampuan diri, serta membangun citra diri dalam menghadapi proses seleksi, agar lebih mudah mendapatkan pekerjaan. mahasiswa fresh graduate cenderung lebih cemas menghadapi proses 
1094 Persiapan Menghadapi Dunia Kerja bagi Mahasiswa Tingkat Akhir dan Lulusan Baru - Masril, Menhard, Zubir, Nusyirwan, Rahmadani Hidayat, Jefriyanto, Maya Rizki Sari, Muhammad Yusuf, Jonnedi

DOI: https://doi.org/10.31004/abdidas.v2i5.431

melamar kerja dibanding menganggur. (Putra, 2017) menyatakan bahwa sebagian besar lulusan baru gagal memberikan kesan yang baik saat wawancara. Mereka bahkan tidak dapat memahami pertanyaan wawancara dasar yang diajukan oleh sebagian besar pemberi kerja. Perasaan cemas saat proses wawancara ditunjukkan dengan merasa tidak memiliki kemampuan, merasa orang lain lebih baik dari dirinya, merasa bahwa kegagalan selau mengikuti, khawatir tidak akan lulus dan tidak bekerja, (Hadi, 2015). Ketidakmampuan ini menyebabkan kelemahan sosial dan ekonomi, terkait dengan pencapaian pekerjaan. Hal ini disebabkan banyak faktor yaitu kurangnya soft skill yang dimiliki mahasiswa, kurangnya informasi mengenai pekerjaan dan kurangnya kepercayaan terhadap kemampuan diri sendiri. Soft skill yang harusnya dimiliki oleh lulusan universitas semasa kuliah, antara lain bidang komputer, Bahasa Inggris, pelatihan enterpreneurship, leadership dan ketenagakerjaan (Nurjanah, 2018). Dengan pengetahuan dan keterampilan tersebut, diharapkan lulusan lebih mudah dalam mendapatkan pekerjaan yang sesuai dengan kompetensi dan karakteristik mereka.

\section{METODE}

Proses belajar mengajar yang dilakukan selama dua tahun terkahir merupakan proses belajar yang dilaksanakan secara daring yang terkadang terpaksa di blend dengan tatap muka. Tidak hanya proses belajar mengajar, hampir semua kegiatan yang dilakukan dilingkungan perguruan tinggi dilaksanakan secara daring, Hal ini dikarenakan masih tingginya kasus penyebaran Covid-19 di seluruh dunia dan indonesia khususnya. Begitu juga dengan kegiatan ini yang juga dilaksanakan dalam bentuk webinar menggunakan aplikasi Zoom Meeting. Kegiatan ini di lakukan pada 21 Agustus 2021. Sasaran yang ingin dicapai dari kegiatan webinar pembekalan ini adalah untuk memberikan tips dan trik kepada mahasiswa dan alumni yang akan mempersiapkan diri untuk terjun ke dunia kerja, memotivasi mahasiswa tingkat akhir dan lulusan baru, memberikan pandangan bagaimana bekerja yang baik disebuah perusahaan, dan meyakinkan peserta langkah apa yang akan diambil setelah lulus nantinya.

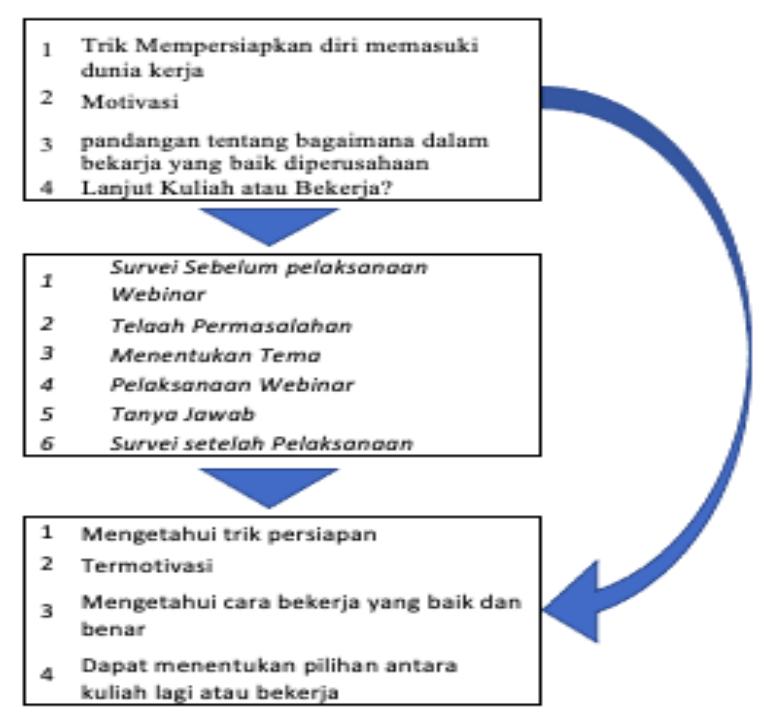

Gambar 1. Kerangka Permasalahan

Alat ukur yang digunakan guna mengukur tercapainya tujuan acara diselenggarakannya kegiatan pembekalan ini adalah peserta di haruskan mengisi form isian yang telah disediakan 
1095 Persiapan Menghadapi Dunia Kerja bagi Mahasiswa Tingkat Akhir dan Lulusan Baru - Masril, Menhard, Zubir, Nusyirwan, Rahmadani Hidayat, Jefriyanto, Maya Rizki Sari, Muhammad Yusuf, Jonnedi

DOI: https://doi.org/10.31004/abdidas.v2i5.431

dalam bentuk google form yang berisi tentang pertanyaan yang disajikan dalam gambar berikut:

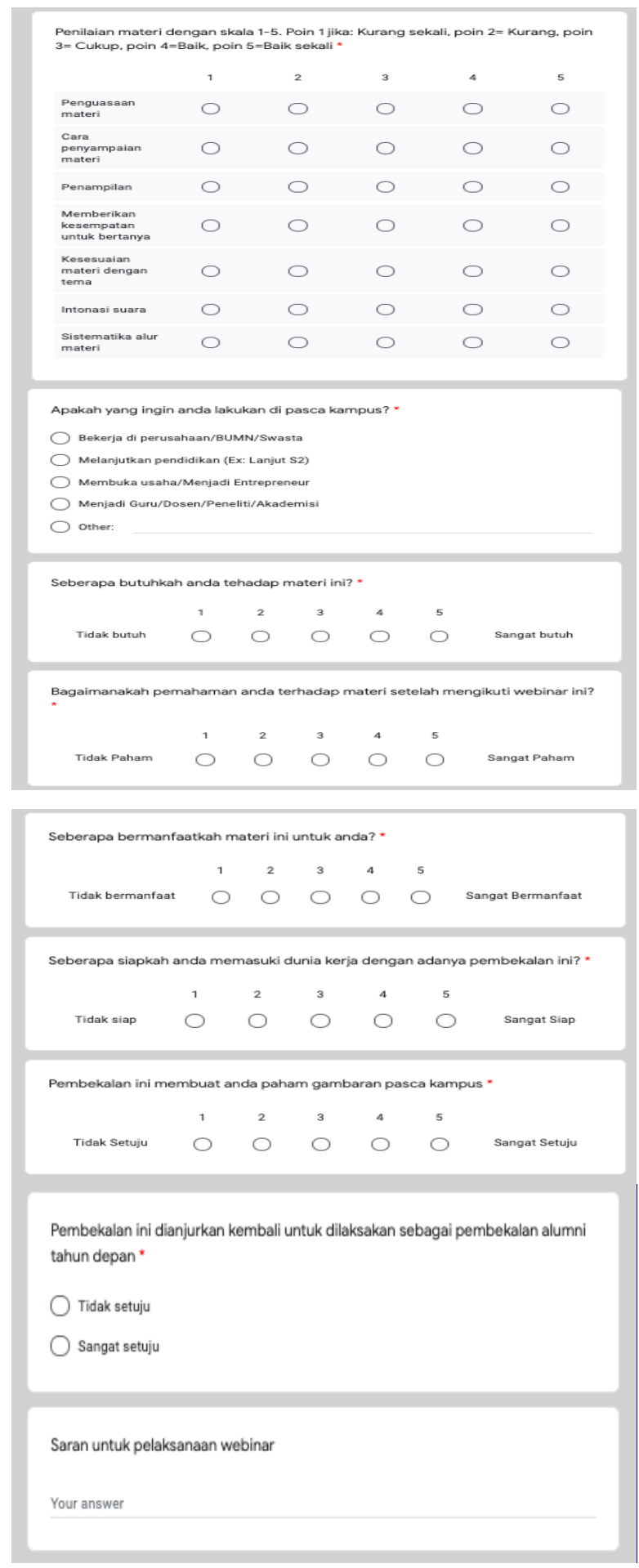

Gambar 2. Form Evaluasi Kegiatan

\section{HASIL DAN PEMBAHASAN}

Webinar ini yang diadakan di STIE Mahaputra dengan tema "Mempersiapkan alumni yang percaya diri dan siap berkonpetisi menghadapi dunia kerja". Webinar ini merupakan bagian dari implementasi dari kegiatan kerjasama antara STIE Mahaputra Riau dengan PT. Agung Automall. Kegiatan webinar ini dilaksanakan menggunakan virtual meeting zoom. Pembekalan ini memberikan pemahaman kepada mahasiswa dan alumni mengenai prinsip the right man in the right place dalam proses seleksi. Acara ini diawali dengan penyampaian materi oleh Bapak Masril, S.E., M.M sekaligus merupakan ketua STIE Mahaputra Riau dan dilanjutkan ke penyampaian materi pembekalan yang disampaikan oleh Kepala Bagian Administrasi Agung Automall yang memiliki banyak pengalaman dalam proses asesmen dalam organisasi, yaitu Ibu Refnelidha Yeva. Melalui pemahaman ini, mahasiswa diharapkan mampu menggali kemampuan diri, meningkatkan kepercayaan diri, serta membangun citra diri yang positif. Pembekalan ini juga memberikan pengetahuan tentang teknis persiapan yang harus dilakukan untuk menghadapi proses seleksi (psikotes dan wawancara). Dengan pengetahuan dan keterampilan tersebut, diharapkan lulusan lebih mudah dalam mendapatkan pekerjaan yang sesuai dengan kompetensi dan karakteristik mereka. Kegiatan Webinar Pembekalan Memasuki Dunia Kerja ini dilaksanakan pada tanggal 21 Agustus 2021 Pukul 09.00 - 10.30 wib. Peserta itu berasal dari dosen-dosen, mahasiswa STIE Mahaputra Riau dan siswa ipi-leppindo jambi 
1096 Persiapan Menghadapi Dunia Kerja bagi Mahasiswa Tingkat Akhir dan Lulusan Baru - Masril, Menhard, Zubir, Nusyirwan, Rahmadani Hidayat, Jefriyanto, Maya Rizki Sari, Muhammad Yusuf, Jonnedi

DOI: https://doi.org/10.31004/abdidas.v2i5.431

dengan Jumlah peserta sebanyak 78 orang yang di siarkan secara live. Peserta sangat antusias dalam mengajukan pertanyaan-pertanyaan.

Pemateri menyampaikan beberapa hal penting yang sekiranya harus diketahui oleh peserta. Mengenai bagaimana menentukan pilihan setelah selesai kuliah. Apakah ingin melanjutkan kuliah atau langsung bekerja diperusahaan atau bahkan berwirausaha. Semua itu tergantung pada pilihan masing-masing sesuai dengan kemampuan dan keinginan serta harus mampu memprioritaskan satu hal. Belajar mengambil keputusan sudah sangat disarankan apabila ingin terus maju dan berkembang. Pembahasan selanjutnya mengenai bagaimana mentukan visi kedepannya dalam bekerja. Sebagai calon perkerja, haruslah mampu menentukan visi. Impian apa yang ingin dicapai kelak ketika sudah bekerja, dan yang tidak kalah pentingnya adalah bagaimana trik menghadapi interview. Sebelum mendatangi sebuah interview, sangat disarankan untuk melakukan riset terlebih dahulu tentang apa, bagaimana, dimana perusahaan yang nantinya menjadi tempat kita untuk melaksanakan interview.

Hasil evaluasi terhadap pelaksanaan kegiatan ini setelah dilakukan penyebaran kuesioner maka diperoleh responden sebanyak 71 orang dan di rangkum ke dalam table 1

Tabel 1. Evaluasi Pelaksanaan

\begin{tabular}{|c|c|}
\hline Penilain Pemateri & $\begin{array}{l}\text { "Pemehaman terhadap materi (point } 5=18 \text {, poin } 4=36, \text { Poin } 3=11 \text {, dan Poin } 2=5 \text { ) } \\
\text { "Bagaimana cara penyampaian materi (point } 5=22 \text {, poin } 4=32 \text {, Poin } 3=15 \text {, dan Poin } 2=2 \text { ) } \\
\text { "Penampilan (point } 5=22 \text {,poin } 4=33 \text {, Poin } 3=13 \text {, Poin } 2=2 \text { dan poin } 1=1 \text { ) } \\
\text { "Kesempatan bertanya (point } 5=31 \text {, poin } 4=18, \text { Poin } 3=21 \text {, Poin } 2=1 \text { ) } \\
\text { "Kesesuaian Materi ((point } 5=33 \text {,poin } 4=24 \text {, Poin } 3=13 \text {, Poin } 2=1 \text { ) } \\
\text { "Intonasi (point } 5=21 \text {,poin } 4=34 \text {, Poin } 3=10 \text {, Poin } 2=6 \text { ) } \\
\text { "Sistematika alur materi (point } 5=31 \text {,poin } 4=18 \text {, Poin } 3=21, \text { Poin } 2=1 \text { ) }\end{array}$ \\
\hline $\begin{array}{l}\text { Seberapa butuhkah anda } \\
\text { tehadap materi ini? }\end{array}$ & $\begin{array}{l}\text { Sebanyak } 49 \text { dari } 71 \text { orang atau lebih dari } 50 \% \text { peserta yang mengisi kuesioner menyatakan } \\
\text { bahwa materi ini sangat mereka butuhkan. }\end{array}$ \\
\hline $\begin{array}{l}\text { Bagaimanakah pemahaman } \\
\text { anda terhadap materi setelah } \\
\text { mengikuti webinar ini? }\end{array}$ & $\begin{array}{l}\text { Sebanyak } 19 \text { orang memberikan poin } 5 \text { untuk pertanyaan ini dan } 34 \text { orang memberikan poin } 4 \text {, } \\
\text { ini artinya pemahaman peserta dalam materi sudah sangat baik. }\end{array}$ \\
\hline $\begin{array}{l}\text { Seberapa bermanfaatkah } \\
\text { materi ini untuk anda? }\end{array}$ & $\begin{array}{l}\text { Dalam hal ini sebanyak } 54 \text { orang peserta memberikan poin } 5 \text {. artinya peserta sangat } \\
\text { merasakan manfaat dari terselenggaranya acara ini. }\end{array}$ \\
\hline $\begin{array}{l}\text { Seberapa siapkah anda } \\
\text { memasuki dunia kerja dengan } \\
\text { adanya pembekalan ini? }\end{array}$ & $\begin{array}{l}\text { Sebanyak } 34 \text { responden menyatakan sangat siap dengan memberikan poin } 5 \text { pada } \\
\text { pertanyaan ini, } 15 \text { orang memberikan poin } 4 \text {, dan } 5 \text { orang memberikan poin } 3\end{array}$ \\
\hline $\begin{array}{l}\text { Pembekalan ini membuat anda } \\
\text { paham gambaran pasca } \\
\text { kampus }\end{array}$ & $\begin{array}{l}30 \text { responden memberikan poin } 5 \text { untuk pertanyaan ini, } 17 \text { Orang memberikan poin } 4 \text {, dan } 7 \\
\text { orang memberikan poin } 3 \text {. artinya sebagian besar peserta paham tentang gambaran yang } \\
\text { akan mereka hadapi masa pasca perkulaiahn selesai. }\end{array}$ \\
\hline
\end{tabular}

Hasil dari evaluasi kegiatan ini menunjukan bahwa tingkat antusias mahasiswa sangat besar. Dapat dilihat dari 78 peserta, sebanyak 71 peserta memberikan respon terhadap kuesioner yang diberikan setelah berlangsungnya kegiatan ini.
Melihat dari respon yang ada, peserta merasa sangat membutuhkan kegiatan ini guna untuk menambah wawasan dan pengetahuan yang selama ini tidak mereka dapatkan di kelas kuliah. Peserta menjadi lebih mampu menentukan pilihan apa 
1097 Persiapan Menghadapi Dunia Kerja bagi Mahasiswa Tingkat Akhir dan Lulusan Baru - Masril, Menhard, Zubir, Nusyirwan, Rahmadani Hidayat, Jefriyanto, Maya Rizki Sari, Muhammad Yusuf, Jonnedi

DOI: https://doi.org/10.31004/abdidas.v2i5.431

yang akan mereka ambil setelah mendengarkan pemateri yang dilanjutkan dengan sesi tanyajawab. Setelah berlangsungnya kegiatan ini, peserta merasa lebih siap dalam memasuki dunia kerja nantinya dan sudah mendapatkan gambaran mengenai situasi seperti apa yang akan mereka hadapi setelah lulus.

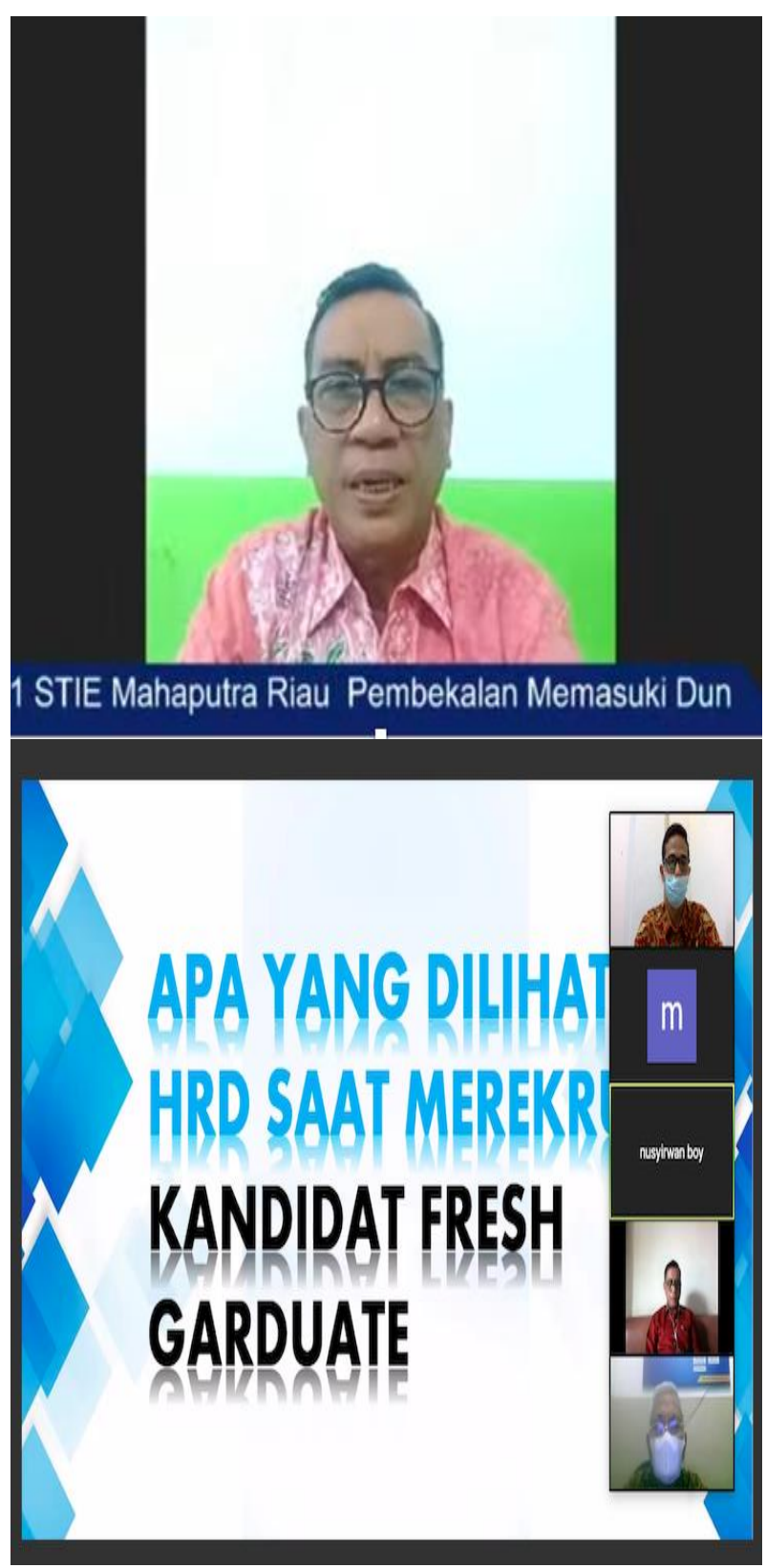

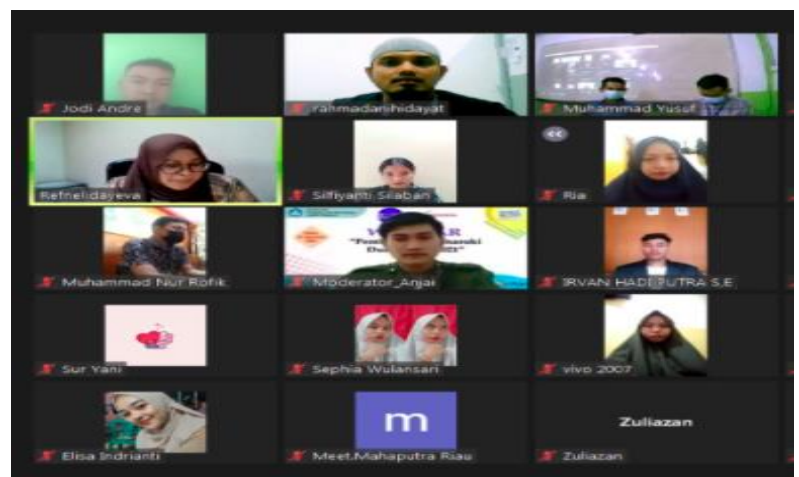

Gambar 3. Pelaksanaan Webinar

\section{SIMPULAN}

Kegiatan webinar pembekalan ini sudah dilaksanakan sesuai dengan yang telah direncanakan dan berjalan dengan sangat baik. Antusias dan respon para peserta juga dapat dirasakan. Hasil evalusai telah sesuai dan akan menjadi pedoman atau pertimbangan dalam melaksanakan acara-acara selanjutnya. Kesuksesan acara ini ditandai dengan adanya kritik dan saran dari para peserta. Ada beberapa hal yang dapat disimpulkan dari kolom komentar yang di himpun dari para peserta antara lain: (1) Pelaksanaan webinar ini sudah sangat baik dan memuaskan dan dapat menambah wawasan dan pengetahuan untuk mereka yang akan memasuki dunia kerja. Kerena antusiasnya para peserta, maka untuk kegiatan selanjutnya diminta untuk memperpanjang waktu kegiatan sehingga akan lebih leluasa untuk melaksanakan tanya jawab.

\section{UCAPAN TERIMAKASIH}

Terimakasih yang sebesar-besarnya kepada STIE Mahaputra Riau selaku penyelenggara kegiatan webinar ini serta lembaga dan bagian- 
1098 Persiapan Menghadapi Dunia Kerja bagi Mahasiswa Tingkat Akhir dan Lulusan Baru - Masril, Menhard, Zubir, Nusyirwan, Rahmadani Hidayat, Jefriyanto, Maya Rizki Sari, Muhammad Yusuf, Jonnedi

DOI: https://doi.org/10.31004/abdidas.v2i5.431

bagian yang terlibat dan peserta webinar yang telah hadir. Kepada Bapak Masril S.E., MM dan team pelaksana lainya yang terlibat ( Bapak Menhard, S.E., M. Pd, Bapak Zubir, S.Pd., M.Ak, Bapak Rahmadani Hidayat, S.E., M.M, Bapak Nusyirwan, S.Kom., M.M, Bapak Jefriyanto, S.E., M.Ak, Ibu Maya Rizki Sari, S.E., M.Si, Bapak Muhammad Yusuf, S.E., M.E., dan Bapak Jonnedi, S.E, Serta semua pihak yang terlibat, serta kepada Ibu Refnelidha Yeva dari Agung Automal yang sudah berbagi ilmu dan pengalamannya kepada seluruh peserta yang telah hadir.

\section{DAFTAR PUSTAKA}

Forbes Coaches Council (2020), Starting A New Chapter: 14 Useful Tips For College Graduates, Https://Www.Forbes.Com/.

Hadi, M. F. Z. (2015). Pemanfaatan Konseling Neuro Linguistic Programming. Jurnal Risalah, 26(4), 174-182.

Krishnan, I. A., Ramalingam, S. J., Ching, H. S., Dan Maruthai, E. 2017. The Selection Practices And Recruitments Of Fresh Graduates In Local Organisation's Job Interview, Journal of Language And Communication, 4(2).

Nurjanah, A. S. (2018). Al-Ittizaan: Jurnal Bimbingan Konseling Islam Kecemasan Mahasiswa Fresh Graduate Dalam Melamar Pekerjaan. Ejournal, 1(2), 35-38.

Prihastuti, N. W. S., \& Rahmawati. (2012). Tingkat Kecemasan Sarjana. 4(3), 2-6.

Putra,

$\mathrm{U}$. (2017). The_Selection_Practices_And_Recruitments . 4(2), 153-167.

Rizky N, Dkk. (2021). Pelatihan Persiapan Menghadapi Dunia Kerja Bagi Mahasiswa Lulusan Baru, Jurnal Pengabdian Kepada Masyarakat Bakti Banua, 2(1), 17-21. 